\title{
AVALIAÇÃO DE DIFERENTES TIPOS DE SUBSTRATO PARA PRODUÇÃO DE POLI(3-HIDROXIBUTIRATO) POR BACILLUS MEGATERIUM
}

\author{
C. P. MAINKA ${ }^{1}$, D. J. L. FACCIN ${ }^{1}$, M. A. Z. AYUB ${ }^{2}$, R. RECH ${ }^{2}$ \\ ${ }^{1}$ Universidade Federal do Rio Grande do Sul - Departamento de Engenharia Química \\ ${ }^{2}$ Universidade Federal do Rio Grande do Sul - Instituto de Ciência e Tecnologia de Alimentos \\ E-mail para contato: debora@enq.ufrgs.br
}

\begin{abstract}
RESUMO - O P(3HB) é um poliéster biodegradável que possui grande potencial de aplicação, porém o fator econômico é um entrave na sua utilização. O preço da fonte de carbono tem papel crucial na economia do processo. Neste trabalho foi avaliada a produção de $\mathrm{P}(3 \mathrm{HB})$ por Bacillus megaterium utilizando diferentes fontes de carbono (efluente da indústria do biodiesel, de laticínio e de transformação da soja). Foram realizados cultivos batelada em estufa incubadora rotatória com retiradas de amostras nos tempos de $0 \mathrm{~h}, 24 \mathrm{~h}$ e $48 \mathrm{~h}$. Para cultivos com soro de leite, permeado de soro e efluente da indústria de soja os valores máximos de acúmulo de polímero foram obtidos no tempo de $24 \mathrm{~h}$, alcançando fração mássica de polímero na biomassa seca de $15 \%, 22 \%$ e $30 \%$ respectivamente. Já para o cultivo com o efluente contendo glicerol o valor máximo de acúmulo, $37 \%$, foi obtido em 48 h. Foi observado acúmulo de polímero nos substratos empregados, evidenciando potencial para produção de $\mathrm{P}(3 \mathrm{HB})$ nos efluentes testados.
\end{abstract}

\section{INTRODUÇÃO}

$\mathrm{Na}$ sociedade atual os plásticos têm papel fundamental. Eles são materiais versáteis de grande qualidade para aplicação nos mais variados produtos. O uso de materiais plásticos é cada vez mais frequente e este vem substituindo matérias-primas convencionais, como papel, papelão, vidros e metais, em função do seu baixo custo e grande durabilidade. Entretanto estes materiais têm despertado grande preocupação devido ao grande volume de plásticos pós-consumo gerado, que aliado à maneira incorreta de descarte ocasiona um sério problema ambiental. $O$ principal motivo é o fato deles não serem biodegradáveis, persistindo como agentes poluidores durante muitos anos e quando depositados em aterros sanitários prejudicam a circulação de gases e a troca de líquidos resultantes do processo de decomposição da matéria orgânica. Sendo assim, está havendo um grande esforço no sentido de desenvolver polímeros biodegradáveis com propriedades similares as dos plásticos convencionais, de modo a substituir estes em aplicações semelhantes.

Os polihidroxialcanoatos (PHAs) são uma classe de biopolímeros que surgem como alternativa a polímeros petroquímicos. A diversidade de PHAs existentes possibilita uma variada 


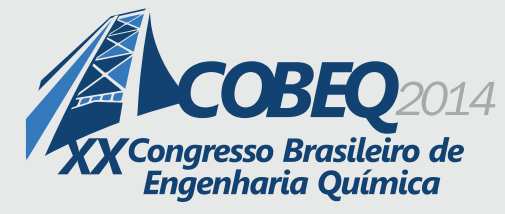

19 a 22 de outubro de 2014

Florianópolis/SC

gama de propriedades, podendo apresentar características que vão de termoplásticos a elastômeros e tendo, assim, potencial para utilização em muitas aplicações. Dentre as características que tornam os PHAs atrativos destaca-se o fato destes serem biodegradáveis. Os PHAs são poliésteres sintetizados por diferentes microrganismos, sendo que mais $30 \%$ das espécies de bactérias que habitam o solo são capazes de sintetizar PHAs. Dentre os PHAs destaca-se o poli(3-hidroxibutirato) ou $\mathrm{P}(3 \mathrm{HB})$. Este possui propriedades semelhantes ao polipropileno. Após a sua descoberta em 1926 por Maurice Lemoigne a partir da bactéria Bacillus megaterium, cerca de 150 diferentes PHAs foram identificados. As bactérias pertencentes ao gênero Bacillus possuem características interessantes para aplicações industriais como tolerância a alta temperatura e alta pressão osmótica, além de apresentarem um rápido crescimento celular. Mas sua característica mais marcante é a capacidade de produzir $\mathrm{P}(3 \mathrm{HB})$ a partir de diversas fontes de carbono, como sacarose, lactose, maltose, glicerol (Lee et al, 1996; Lenz et al., 2004).

Estudos em andamento não só visam os aspectos sustentáveis dos PHAs, mas também buscam considerar o fator econômico que até hoje é a principal desvantagem e entrave na utilização e aplicação mais ampla dos PHAs, bem como do seu uso como substituto dos polímeros petroquímicos. A fim de serem competitivos com plásticos comuns, os custos de produção dos PHAs devem ser minimizados. Os preços das matérias-primas para a produção de PHAs desempenham um papel crucial para a economia do processo. Atualmente as matériasprimas utilizadas para a produção de PHAs são substratos de valor elevado, como sacarose, óleos vegetais e ácidos graxos. A busca por substratos mais baratos cada vez mais vem sendo estudada, como a utilização de resíduos industriais (Cavalheiro et al., 2009; Koller et al., 2008; López et al., 2012; Posada et al. 2011).

Inserido neste contexto, o presente trabalho trata da avaliação de diferentes tipos de substrato para produção de $\mathrm{P}(3 \mathrm{HB})$ pela $B$. megaterium. Foi avaliado o crescimento de biomassa, bem como a produção de $\mathrm{P}(3 \mathrm{HB})$, a partir de fontes de carbono provenientes de efluentes industriais. Os efluentes analisados foram: efluente da indústria do biodiesel (glicerol residual como alternativa para reaproveitamento de resíduo da produção de biodiesel, uma vez que a sua crescente produção de tem gerado um excedente de glicerol e, consequentemente, uma queda no seu preço de venda), efluente da indústria de laticínios (soro de leite e permeado de soro, devido a sua grande disponibilidade: $80 \%$ a $90 \%$ do volume de leite transformado) e efluente da indústria de transformação da soja.

\section{MATERIAIS E MÉTODOS}

\subsection{Microrganismos e meio de cultura para inóculo}

O microrganismo empregado foi a bactéria Bacillus megaterium DSMZ $32^{\mathrm{T}}$. As células foram mantidas a $-18{ }^{\circ} \mathrm{C}$ em solução crioprotetora $(20 \%$ em volume de glicerol). Para a reativação celular a fim do seu emprego como inóculo, realizou-se o cultivo das células em frascos cônicos contendo meio mineral, conforme descrito em Wang e Lee (1997), acrescido de $16 \mathrm{~g} \cdot \mathrm{L}^{-1}$ de sacarose e $2 \mathrm{~g} \cdot \mathrm{L}^{-1}$ de sulfato de amônio. Os frascos de pré-inóculo foram mantidos 


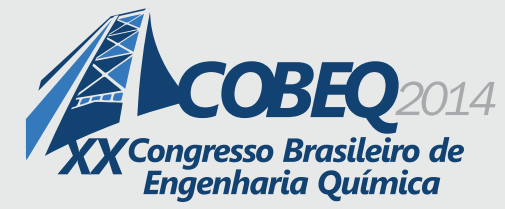

durante $16 \mathrm{~h}$ em estufa incubadora rotatória a $140 \mathrm{rpm}$ e temperatura de $30^{\circ} \mathrm{C}$. Após este período foi adicionado ao cultivo, em cada experimento, $2 \%$ desse inóculo em relação ao volume do meio de cultivo.

\subsection{Cultivos usando diferentes fontes de carbono}

Experimentos foram realizados com a finalidade de avaliar a produção de $\mathrm{P}(3 \mathrm{HB}) \mathrm{e}$ biomassa utilizando diferentes fontes de carbono. Os experimentos foram realizados em estufa incubadora rotatória, em frascos cônicos de $250 \mathrm{~mL}$ contendo $50 \mathrm{~mL}$ de meio de cultivo, com temperatura e agitação de $30{ }^{\circ} \mathrm{C}$ e $140 \mathrm{rpm}$, respectivamente. Todos os cultivos foram realizados em duplicata. Os dados de biomassa e acúmulo de polímero apresentados foram obtidos no tempo de $24 \mathrm{~h}$ e $48 \mathrm{~h}$ em cultivos independentes.

Utilizou-se como fonte de carbono efluente indústria do biodiesel, efluente indústria de laticínios (soro de leite e permeado de leite) e efluente da indústria de soja. Para comparação entre cultivos com diferentes fontes de carbono a concentração empregada de cada efluente foi tal que garantisse a mesma concentração de carbono presente em $16 \mathrm{~g} \cdot \mathrm{L}^{-1}$ de sacarose. A quantidade utilizada é baseada na razão carbono/nitrogênio ótima apresentada no trabalho de Faccin et al. (2009). Quando necessário, o pH inicial foi ajustado para 7,0.

Efluente da indústria do biodiesel: A Tabela 1 apresenta a composição do efluente da indústria de biodiesel. Este efluente também foi suplementado com meio mineral, conforme descrito em Wang e Lee (1997), e $2 \mathrm{~g} \cdot \mathrm{L}^{-1}$ sulfato de amônio.

Tabela 1 - Composição do efluente da indústria do biodiesel

\begin{tabular}{lr}
\hline Glicerol & $81,78 \%$ \\
Cinzas & $5,82 \%$ \\
Cloretos & $6,00 \%$ \\
\hline
\end{tabular}

Efluente da indústria de laticínio: Foram utilizados como fonte de carbono o soro e o permeado de leite. A composição do soro é variável e pode ser afetada pela variedade de queijo produzido, além do tratamento térmico do leite, manipulação e outros fatores (CHEEKE et al., 1973; SCHINGOETHE et al., 1980). A composição típica do soro e dos produtos obtidos da ultrafiltração é apresentada na Tabela 2.

Tabela 2 - Composição típica do soro e permeado de leite obtido através de ultrafiltração - fator de concentração igual a 5 (volume/volume) (adaptado de HOFFMANN, 2003).

\begin{tabular}{lccccc}
\hline \multirow{2}{*}{ Produto } & \multicolumn{5}{c}{ Constituintes (\%) } \\
& Proteínas & Lactose & Gordura & Sais & Proteína/Lactose \\
\hline Soro & 0,9 & 4,9 & 0,3 & 0,6 & 0,18 \\
Permeado & 0,1 & 5,0 & 0,0 & 0,5 & 0,02 \\
\hline
\end{tabular}




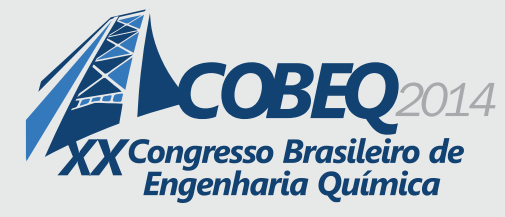

Efluente da indústria de soja: $O$ efluente da indústria de soja foi obtido do resíduo intermediário do processo secundário de tratamento de efluente de uma indústria de produção de proteínas isoladas de soja, proteínas texturizadas e concentradas de soja, lecitinas e fibras de soja. Segundo Cassini (2008), o efluente gerado na produção de isolados proteicos a base de soja é composto, basicamente, por proteínas e carboidratos solúveis em meio aquoso, atingindo elevados valores de DQO, além de altos teores de nitrogênio. A composição típica desse efluente encontra-se na Tabela 3.

Tabela 3 - Composição típica do efluente de uma indústria de produção de isolados proteicos a base de soja (adaptado de Salvadori et al., 2012)

\begin{tabular}{lc}
\hline Parâmetro & Composição $\left(\mathbf{m g} \cdot \mathbf{L}^{\mathbf{- 1}}\right.$ ) \\
\hline DQO & 17.000 \\
Teor proteico & 4.200 \\
Sólidos Suspensos Totais & 3.800 \\
Sólidos Totais & 18.000 \\
\hline
\end{tabular}

$\mathrm{O}$ efluente foi esterilizado utilizando filtração com membrana de $0,22 \mu \mathrm{m} \mathrm{e} \mathrm{o} \mathrm{pH}$ foi corrigido de 3,91 para 7,06.

\subsection{Métodos analíticos}

Biomassa: A determinação da biomassa total foi feita através de medidas de massa celular seca (gravimetria). Amostras em duplicata $(10 \mathrm{~mL})$ foram coletadas dos cultivos após $24 \mathrm{~h}$ e 48 $\mathrm{h}$, centrifugadas durante $15 \mathrm{~min}$ a $3500 \mathrm{rpm}$. Os sobrenadantes foram retirados e reservados e os precipitados foram lavados com água destilada e novamente centrifugadas nas mesmas condições e então colocados em estufa até atingirem massa constante.

Poli(3-hidroxibutirato): A quantidade de $\mathrm{P}(3 \mathrm{HB})$ foi determinada através do método descrito por Riis e Mai (1988). O método consiste na quebra do polímero por meio de propanólise com subsequente quantificação utilizando cromatografia gasosa. Pesou-se as células secas em um frasco e posteriormente foi adicionado $2 \mathrm{~mL}$ de 1,2-dicloroetano, $2 \mathrm{~mL}$ de $\mathrm{n}$ propanol acidificado (4 partes de n-propanol para 1 parte de ácido clorídrico) e $2 \mu \mathrm{L}$ de solução de padrão interno, composto por $2 \mathrm{~g}$ de ácido benzóico em $50 \mathrm{~mL}$ de n-propanol. $\mathrm{O}$ frasco, hermeticamente fechado, foi então colocado em banho a $100{ }^{\circ} \mathrm{C}$ por $2,5 \mathrm{~h}$ com agitação intermitente a cada $30 \mathrm{~min}$. Posteriormente, ele foi resfriado até atingir a temperatura ambiente, foram adicionados $4 \mathrm{~mL}$ de água destilada e submetido a agitação em vortex. Da fase orgânica resultante (mais densa) é obtido o cromatograma. Uma curva de calibração é construida a fim de correlacionar-se as áreas de massas conhecidas de $\mathrm{P}(3 \mathrm{HB})$ padrão (Sigma-Aldrich) com a área do padrão interno. Foi utilizado um cromatógrafo gasoso da marca Perkin Elmer, com detector de ionização de chama com uma coluna capilar PE-WAX $30 \mathrm{~m} \times 0,25 \mathrm{~mm}$. 


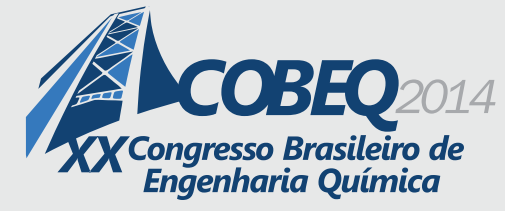

\section{RESULTADOS E DISCUSSÃO}

A Figura 1 apresenta valores de concentração de biomassa total (a), pH (b) e concentração de $\mathrm{P}(3 \mathrm{HB})$ (c) obtidos nos cultivos com as diferentes fontes de carbono nos tempos de $0 \mathrm{~h}, 24 \mathrm{~h} \mathrm{e}$ $48 \mathrm{~h}$. Observa-se que houve crescimento em todos os meios testados indicando que é possível a utilização dos efluentes como meio de cultura para crescimento da B. megaterium. Os cultivos utilizando glicerol residual apresentaram valores de biomassa ligeiramente maiores em $48 \mathrm{~h}$. Nos cultivos com os efluentes da indústria de laticínios (soro e permeado), bem como com o efluente da indústria de soja, verifica-se que a maior concentração de biomassa foi em $24 \mathrm{~h}$ de cultivo. Houve uma acentuada queda do $\mathrm{pH}$ do meio quando no cultivo com glicerol residual. Esta queda no valor de $\mathrm{pH}$ também ocorre quando sacarose é utilizada como fonte de carbono na produção de $\mathrm{P}(3 \mathrm{HB}$ ) com B.megaterium (Faccin et al.,2009). Para as outras fontes de carbono utilizadas, verificou-se um aumento no $\mathrm{pH}$ do meio. A alcalinização do meio não era esperada e mais estudos devem ser realizados para verificação. Koller et al. (2008) trabalharam com Pseudomonas hydrogenovora para produção de $\mathrm{P}(3 \mathrm{HB})$ a partir de glicose e galactose (monossacarídeos que compõe a lactose, abundante nos efluentes de soro e permeado de leite) e observaram acidificação do meio de cultivo. No que diz respeito a produção de $\mathrm{P}(3 \mathrm{HB})$, foco principal do trabalho, observa-se que a $B$. megaterium apresentou produção em todos os substratos empregados no presente estudo, evidenciando potencial para utilização dos efluentes testados não só para crescimento celular, mas também para produção de $\mathrm{P}(3 \mathrm{HB})$. Para melhor comparação os resultados de acúmulo percentual de polímero (fração mássica de polímero na biomassa seca) são apresentados na Tabela 4. Nas amostras cultivadas com os efluentes da indústria de laticínios (soro e permeado), bem como com o efluente da indústria de soja, verificase maior produção de polímero em $24 \mathrm{~h}$ e decréscimo na concentração de polímero, indicando que houve consumo do mesmo. Cabe salientar que para estes últimos efluentes descritos não houve suplementação de micronutrientes e nem adição de fonte de nitrogênio como empregado para o glicerol residual. A falta de algum nutriente pode levar ao consumo de $\mathrm{P}(3 \mathrm{HB})$. Além disso, o fato do $\mathrm{pH}$ do meio ser também pode ter contribuído para o consumo, uma vez que o valor baixo de $\mathrm{pH}$ pode inibir o consumo de polímero como substrato. No cultivo utilizando efluente da indústria de soja obteve-se $30 \%$ de acúmulo de polímero. Para cultivos com soro de leite e permeado de soro foram alcançadas frações mássicas de polímero na biomassa seca de $15 \%$ e $22 \%$ respectivamente. Valores ligeiramente maiores foram obtidos no trabalho de Koller et al. (2008) que compararam a produção de PHA pela Pseudomonas hydrogenovora DSM 1749 utilizando um meio sintético com açúcares puros (glicose e galactose) e o permeado de soro de leite hidrolisado e obtiveram acúmulo de polímero de, respectivamente, $26 \%$ e $28 \%$ indicando que a produção a partir do permeado foi maior que utilizando os açúcares puros.

Tabela 4. Acúmulo de polímero nas células após 24 h e 48 h para as diferentes fontes de carbono

\begin{tabular}{lcr}
\hline Fonte de carbono & $\mathbf{2 4 h}$ & \multicolumn{1}{c}{$\mathbf{4 8 ~ h}$} \\
\hline Glicerol residual & $25 \% \pm 3 \%$ & $37 \% \pm 3 \%$ \\
Soro de leite & $15 \% \pm 1 \%$ & $5 \% \pm 1 \%$ \\
Permeado de leite & $22 \% \pm 2 \%$ & $18 \% \pm 3 \%$ \\
Efluente indústria de soja & $30 \% \pm 4 \%$ & $22 \% \pm 1 \%$ \\
\hline
\end{tabular}




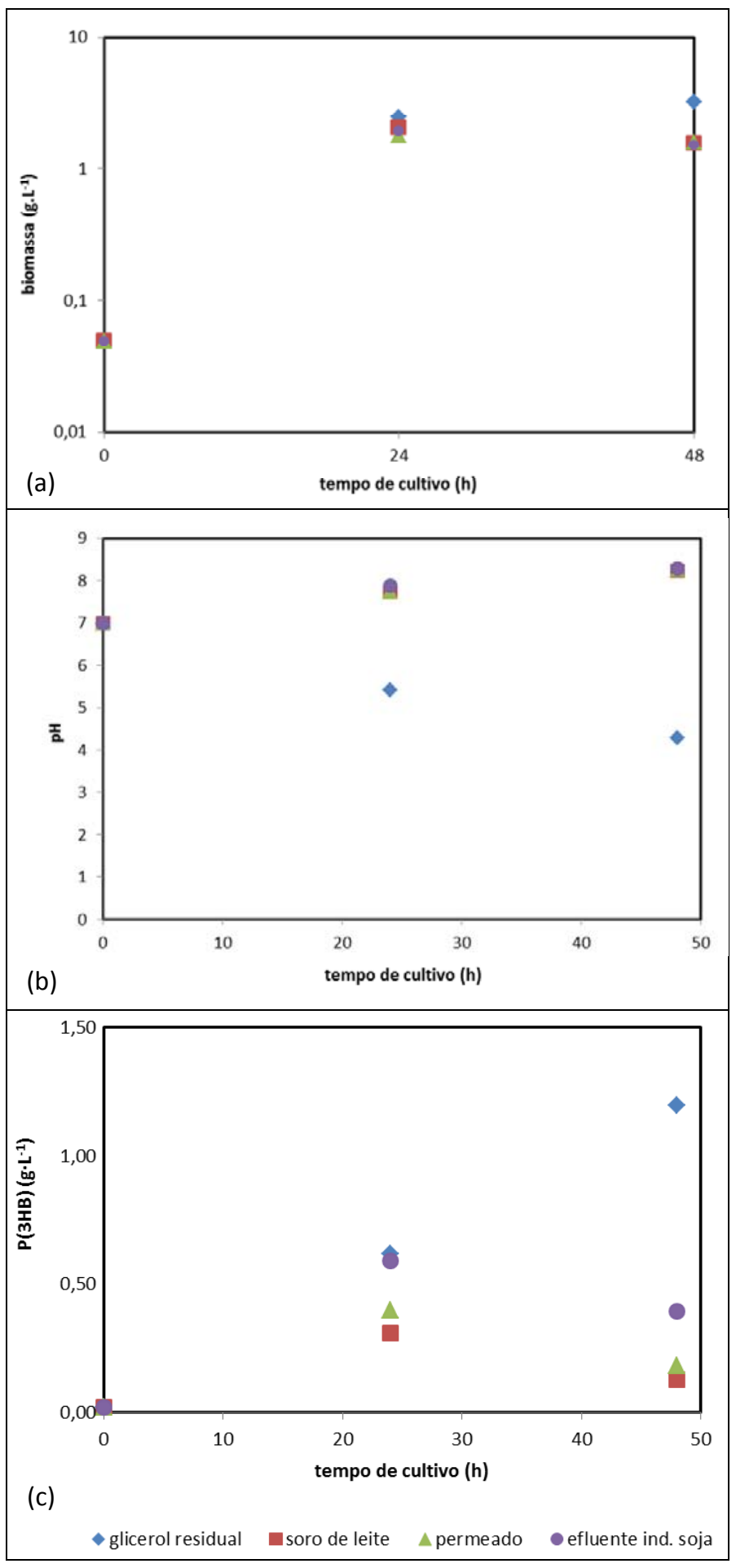

Figura 1. Curva de crescimento celular (a), variação de $\mathrm{pH}$ (b) e produção de polímero (c) para o cultivo com as diferentes fontes de carbono. 


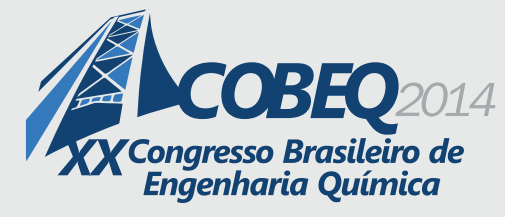

19 a 22 de outubro de 2014

Florianópolis/SC

No cultivo utilizando efluente da indústria de biodiesel (glicerol residual), a maior concentração de $\mathrm{P}(3 \mathrm{HB})$ foi alcançada em $48 \mathrm{~h}$ de cultivo. Cabe ressaltar que foi utilizado glicerol residual oriundo da produção de biodiesel sem nenhuma purificação ou tratamento para utilização como meio de cultura. Atingiu-se acúmulo de $37 \%$ (fração mássica de polímero na biomassa seca). Posada et al. (2011) estudaram a produção de $\mathrm{P}(3 \mathrm{HB})$ por Cupriavidus necator utilizando duas qualidades de glicerol, $88 \%$ e $98 \%$ em peso e obtiveram acúmulo de $\mathrm{P}(3 \mathrm{HB})$ em torno de $38 \%$ e $53 \%$ de $\mathrm{P}(3 \mathrm{HB})$, respectivamente. Cabe observar que os referidos autores realizaram tratamento para purificação do resíduo de glicerol para utilizá-lo como fonte de carbono Cavalheiro et al. (2009) também utilizaram a bactéria Cupriavidus necator DSM 545 para avaliar a produção de $\mathrm{P}(3 \mathrm{HB})$ utilizando glicerol residual e glicerol comercial. Utilizando o glicerol residual os autores obtiveram $38 \%$ de acúmulo de $\mathrm{P}(3 \mathrm{HB})$, enquanto que para o glicerol comercial este valor chegou em $62 \%$.

\section{CONCLUSÕES}

Neste trabalho, realizou-se cultivo batelada de B. megaterium durante $48 \mathrm{~h}$ em estufa incubadora rotatória em quatro meios de cultivos diferenciados utilizando efluentes. Foi verificado que $B$. megaterium acumulou polímero em todos os substratos empregados no presente estudo, evidenciando potencial para produção de $\mathrm{P}(3 \mathrm{H})$. Sendo o custo da matériaprima fator determinante para a economia do processo, a utilização de efluentes industriais se mostra vantajosa. Assim é possível verificar que os efluentes testados no presente trabalho apresentam potencial para aplicação com a B. megaterium, necessitando de otimização das condições para aumento da produção de $\mathrm{P}(3 \mathrm{HB})$.

\section{REFERÊNCIAS}

CASSINI, A. C. Estudo de processos alternativos no pré-tratamento de efluentes provenientes da produção de isolados proteicos. 2008. 195 f. Tese de Doutorado - Programa de PósGraduação em Engenharia Química, Departamento de Engenharia Química, Universidade Federal do Rio Grande do Sul, Porto Alegre, RS, Brasil, 2008.

CAVALHEIRO, J.M.B.T., DE ALMEIDA, M.C.M.D., GRANDFILS, C., DA FONSECA, M.M.R. Poly(3-hydroxybutyrate) production by Cupriavidus necator using waste glycerol. Process Biochem., v. 44, p. 509-515, 2009.

CHEEKE, P.R.; DAVISON, T.P.; MEYER, R.O.; STANGEL, D.E. Utilization of dried whey by growing finishing swine. Feedstuff, v. 45, n. 28, p. 25, 1973.

FACCIN, D. J. L.; MARTINS, I.; CARDOZO, N. S. M.; RECH, R.; AYUB, M. A. Z.; ALVES, T. L. M.; GAMBETTA, R.; SECCHI, A. R. Optimization of C:N ratio and minimal initial carbon source for poly(3-hydroxybutyrate) production by Bacillus megaterium. J. chem. technol. biotechnol., v. 84, n. 12, p. 1756-1761, 2009.

HOFFMANN, C. M. Estudo da utilização de concentrado proteico de soro de queijo ultrafiltrado (CPSU), em requeijão cremoso. Dissertação de mestrado - Programa de Pós-Graduação em Ciências de Alimentos, Departamento de Ciência e Tecnologia de Alimentos, Centro de Ciências Agrárias, Universidade Federal de Santa Catarina, Florianópolis, SC, Brasil, 
2003.

KOLLER, M.; BONA, R.; CHIELLINI, E.; FERNANDES, E. G.; HORVAT, P.; KUTSCHERA, C.; HESSE, P.; BRAUNEGG, G. Polyhydroxyalkanoate production from whey by Pseudomonas hydrogenovora. Bioresour. technol., v. 99, p. 4854-4863, 2008.

KOMINEK, L. A.; HALVORSON, H. O. Metabolism of poly-beta-hydroxybutyrate and acetoin in Bacillus cereus. J. bacteriol., v. 90, n. 5, p. 1251-1259, 1965.

LEE, S. Y. Bacterial polyhydroxyalkanoates. Biotechnol. Bioeng, v. 49, n. 1, p. 1-14, 1996.

LENZ, R. W. e MARCHESSAULT, R. H. Bacterial Polyesters: Biosynthesis, Biodegradable Plastics and Biotechnology. Biomacromol., v. 6, n. 1, p. 1-8,2005.

LÓPEZ, J.; NARANJO, J.; HIGUITA, J.; CUBITTO, M.; CARDONA, C.; VILLAR, M. Biosynthesis of PHB from a new isolated Bacillus megaterium strain: Outlook on future developments with endospore forming bacteria. Biotechnology and Bioprocess Engineering, v. 17, n. 2, p. 250-258, 2012.

PHILIP, S.; SENGUPTA, S.; KESHAVARZ, T.; ROY, I. Effect of Impeller Speed and pH on the Production of Poly(3-hydroxybutyrate) Using Bacillus cereus SPV. Biomacromol., v. 10, n. 4, p. 691-699, 2009.

POSADA, J. A.; NARANJO, J. M.; LÓPEZ, J. A.; HIGUITA, J. C.; CARDONA, C. A. Design and analysis of poly-3-hydroxybutyrate production processes from crude glycerol. Process Biochem., v. 46, n. 1, p. 310-317, 2011.

RIIS, V. e MAI,W. Gas chromatographic determination of poly- $\beta$-hydroxybutyric acid in microbial biomass after hydrochloric acid propanolysis. J. chromatogr., n. 445, p.285-289, 1988.

SALVADORI, S.; KONRAD, O.; CASARIL, C.; LUMI, M.; SCHMITZ, M. Geração de biogás a partir de lodo de estação de tratamento de efluentes na fabricação de proteína isolada de soja. Engenharia Ambiental - Espírito Santo do Pinhal, v. 9, n. 1, p. 128-141, 2012.

SCHINGOETHE, D. J.; SKYBERG, E. W. Lactation and growth of dairy cows and steers from large amounts of dried whey. Journal Dairy Science 1981, v. 64, p. 1571-1578, 1980.

WANG, F. L.; LEE, S. Y. Poly(3-hydroxybutyrate) production with high productivity and high polymer content by a fed-batch culture of Alcaligenes latus under nitrogen limitation. Applied and Environmental Microbiology, v. 63, n. 9, p. 3703-3706, Sep 1997. 